\title{
Iconografía de Cicerón en manuscritos: Un testimonio de Recepción clásica
}

\section{Introducción: Panorama general y antecedentes}

La representación de los autores griegos y latinos en las diferentes disciplinas artísticas y soportes es un aspecto relevante de la Recepción clásica. Respecto a Cicerón, antes de centrar mi atención en los manuscritos, es necesario señalar que, fuera de este ámbito artístico, en la Edad Media y el Renacimiento su efigie aparece en representaciones de la Siete Artes Liberales junto a una dama que personifica a Retórica, porque es considerado el maestro por excelencia de esta disciplina. Así lo vemos, por ejemplo, en la arquivolta exterior del pórtico derecho de la Catedral de Chartres; en el Triunfo de Santo Tomás de Aquino, fresco de Andrea de Bonaiuto, en la Iglesia de Santa María Novella en Florencia; en la Allégorie des Arts libéraux óleo del pintor Biagio d'Antonio Tucci que custodia el Museo Condé de Chantilly; en la representación de las Artes Liberales con la que Giovanni dal Ponte decora el frontal de un arcón que hoy está en el Museo del Prado de Madrid; en el fresco de las Artes Liberales en la Capilla de Invierno de la Catedral de Nôtre Dame de Le Puy-en-Velay; en los frescos de la Biblioteca de El Escorial realizados por Pellegrino Tibaldi y sus colaboradores o en la Biblioteca del Castillo de Windhag. Por otro lado, como autor destacado en el ámbito de la filosofía aparece, por ejemplo, en un plato de bronce del siglo XII junto a Filosofía, Sócrates, Platón, Prisciano, Aristóteles y Boecio y en un cuenco de madera para la limosna de la catedral de Halberstadt (Alemania), junto a Virgilio, Juvenal, Platón, Aristóteles, Diógenes, Hipócrates, Galeno, etc. ${ }^{1}$ Tanto en un caso como en otro se le representa en calidad de autor canónico y filósofo. Sin embargo, en el Quattrocento italiano el autor de las Catilinarias fue más bien un icono de las virtudes cívicas y como tal aparece en las galerías de hombres famosos. ${ }^{2}$ También la pintura de gran formato y la escultura de los siglos XVII a $\mathrm{XX}$ lo representan más en su faceta de hombre de estado y de orador que en la de autor literario. ${ }^{3}$

1 Knipp 2002, 379-382, 403, 405.

2 Cf. Joost-Gaugier 1985; Marsh 2013, 316-317; Jones/Kilpatrick 2007, 377-9.

3 Martín Puente 2021a.

๑ OpenAccess. ( 2022 Cristina Martín Puente, published by De Gruyter. (cc)BY under the Creative Commons Attribution 4.0 International License. 
Pero, dejando por el momento estas interesantes representaciones, que merecen un estudio detallado aún no realizado, me centraré en el retrato de Cicerón en los manuscritos, ${ }^{4}$ que, por supuesto, es ideal y ficticio y, además, extraordinariamente parecido a los de Dante, Petrarca o Boccaccio de esa época. En general, siempre tiene el propósito de embellecer ediciones más o menos lujosas hechas para el disfrute del lector y subrayar que se trata de un autor digno de ser leído y estudiado en la escuela, a pesar de ser pagano, pero, dependiendo de los casos, tiene funciones específicas. Cuando aparece en la primera página o en el interior de libros que contienen sus obras, ya sea en latín o en traducciones, su imagen pretende garantizar que Cicerón es el autor de esa obra, por eso, es una prueba más de que la archiconocida Rethorica ad Herennium en estos siglos era considerada de manera unánime del arpinate. ${ }^{5}$ En una miscelánea que recoge una galería de autores canónicos, donde aparece en un folio junto a Retórica y en otro acompañado de Marciano Capela, estamos ante retratos muy similares a los excultóricos y pictóricos mencionados antes, que lo destacan como máximo representante de la Retórica. Finalmente la escena de la decapitación de Cicerón en la versión francesa del De casibus virorum illustrium de Boccaccio, no solo ilustra el texto, también lo señala como un personaje histórico digno de ser conocido como un referente moral.

Cicerón fue un autor sumamente importante en la Antigüedad y desde el siglo II hasta el IV paganos y cristianos ${ }^{6}$ estudiaron en profundidad sus obras con distintos objetivos. ${ }^{7} \mathrm{Su}$ transmisión se resintió entre el 550 y el 750, pero a partir de ese momento y, sobre todo, desde Petrarca, que lo tenía entre sus autores predilectos, siguió siendo un autor de referencia fundamental, aunque cada una de sus obras corrió diferente suerte. La Rhetorica ad Herennium, el De inventione, los Topica, las obras filosóficas y algunos discursos fueron muy copiados y tuvieron gran éxito. Sin embargo, el De oratore no fue descubierto hasta 1421 y el De republica hasta 1819, pero muchos otros textos se perdieron. ${ }^{8}$ Las traducciones, como la del tratado De inventione al francés de Jean d'Antioche en 1282, la del Pro Marcello al italiano de Brunetto Latini, las que

4 Este tema también ha sido estudiado por Lazzi 2000 y 2012 en otros manuscritos. Este trabajo es complementario a los suyos.

5 Sobre esta cuestión, cf. el reciente trabajo de Calboli 2020.

6 Lo imitaron Minucio Félix en su Octavius (inspirado en el De natura deorum), Lactancio en sus Divinae institutiones, San Ambrosio en el De officiis clericorum (inspirado en el De officiis), San Jerónimo, San Agustín, etc.

7 Cf., por ejemplo, MacCormack 2013 y Kendeffy 2015.

8 Cf. Putnam1896-1897, XII; MacCormack 2013, 7-27; Morrás 1996; Reynolds 1983, XIII-XLIII; 54-142; Ward 2015; Marsh 2013. 
hicieron en el siglo XV Anjourrant Bourré y XV Laurent de Premierfait al francés, las de Alonso de Cartagena al castellano, etc. contribuyeron a su mayor difusión. ${ }^{9}$ Poco a poco eruditos como Petrarca mostraron un gran interés por el personaje $\mathrm{e}^{10}$ y sin duda propiciaron que se le retratara en miniaturas, al igual que ocurre con otros autores. ${ }^{11}$

Aquí mostraré una serie de retratos de Cicerón que aparecen en manuscritos de los siglos XIII al XV. En los que contienen la Rhetorica ad Herennium, De senectute, De amicitia, De finibus, De officiis y Pro Marcello, los retratos dan sello de autenticidad a la autoría ciceroniana de esas obras. Cuando aparece junto a Retórica, el retrato lo muestra como uno de los máximos representantes de esta disciplina. Y, cuando aparece una miniatura con su decapitación en la versión francesa del De casibus virorum illustrium de Boccaccio, Cicerón es retratado como un hombre de estado digno de admiración por sus virtudes cívicas y morales.

\section{Los retratos en los manuscritos}

Las primeras seis miniaturas ${ }^{12}$ (de 2.1. a 2.5.) retratan a Cicerón en tanto que máxima autoridad en la retórica, ya sea junto a una figura femenina que representa a esta disciplina, una de las siete Artes Liberales, ya sea como autor de la Rhetorica ad Herennium. Las diez siguientes (de 2.6 a 2.12) lo presentan como filósofo $\mathrm{y}$, en menor medida, como orador. Las dos últimas miniaturas (2.13 y

9 Respecto a Brunetto Latini, cf. Lorenzi 2013, respecto a Laurent de Premierfait, cf. Bozzolo 2004 y, respecto a Alonso de Cartagena, que tradujo también el De inventione entre 1424 y 1432 a petición de Don Duarte, cf. Morrás 1991, 221 y Olivetto 2010, 231.

10 Boccaccio también habla de él en la recopilación de biografías titulada De cassibus virorum illustrium (entre 1355 y 1374), cuya segunda traducción francesa de Laurent de Premierfait, con miniaturas, tuvo enorme éxito. Jacopo Angeli tradujo al latín en 1401 la biografía de Cicerón que Plutarco incluyó en las Vidas paralelas. Leonardo Bruni escribió Cicero novus (1415), que gozó de gran fama. Sicco Polenton le dedicó un amplio espacio en su tratado Scriptorum illustrium latinae linguae libri XVIII (1437) (cf. Cook 2013).

11 Por ejemplo, encontramos retratos de Séneca en diversos manuscritos que trasmiten su obra, así como de este autor y su esposa Paulina en el Des cleres et nobles femmes (BL Royal $20 \mathrm{C} \mathrm{V}$ fol. 143; BL Royal $16 \mathrm{G} \mathrm{V}$ fol. 110) y en el Livre des femmes nobles et renommees (BnF Français 598, fol. 139v), ambas traducciones francesas anónimas del De claris mulieribus de Boccaccio. Sin embargo, aparece un retrato de Séneca sin Paulina en el Roman de la Rose (BL Harley 4425, fol. 59v.). (Martín Puente 2021a). Algo similar ocurre con Ovidio (Martín Puente/Andújar Cantón 2017, 437).

12 Recojo aquí todos retratos de Cicerón de cuya existencia tengo constancia hasta la fecha, un total de 18. 
2.14), en las que le dan muerte por orden de Antonio, lo muestran como excónsul y hombre de estado.

2.1. El manuscrito München, Bayerische Staatsbibliothek, Cod. lat. 2599 (Aldersbach, Kreis Passau, c. 1225-1230) ${ }^{13}$ recoge los Sermones de Petrus Comestor, el tratado Musica des Johannes, que corresponde al De musica cum tonario de Jean d'Afflighem, y finalmente, desde el folio 102v hasta el 112r, una galería de miniaturas sin colorear integrada por cada una de las Artes Liberales acompañada por uno de sus máximos representantes y, a continuación, por los autores que constituirían el canon vigente en esa escuela, entre ellos Cicerón. ${ }^{14}$ Dentro de esta última sección, encontramos en la parte superior izquierda del folio $104 \mathrm{v}$ la leyenda Rethorice studio verba polire scio, y dentro un doble arco románico que reposa sobre dos columnas, a la izquierda, a la personificación de la Retórica como una joven y bella dama con una espada y, a la derecha, a un Cicerón muy joven y apuesto, sin barba, con vestimenta corta y quizá con un birrete. Este porta una flecha en la mano izquierda y un filacterio en la derecha sujeto también por Retórica en el que leemos artem disce meam qui vis bene dicere causam. ${ }^{15}$ Ambos son identificados con sendas inscripciones en mayúsculas en el doble arco: Retorica y Tullius. Cicerón fue el retórico con más predicamento en la Edad Media gracias a que el De inventione y la Rhetorica ad Herennium, consideradas sus obras de juventud, se convirtieron en los pilares del aprendizaje de la retórica en la Edad Media.

13 Klemm 1998, 91.

14 Cicerón sería, por tanto, un autor canónico en Aldersbach (Klemm 1978), al igual que lo era en las escuelas de Italia (Ward 2015, 313).

15 Cf. Klemm 1998, 93. El retrato del folio 104v se puede ver en https://www.bildindex.de/docu ment/obj00074132?part=13\&medium=fm102311 (visto 9.12.2019). 


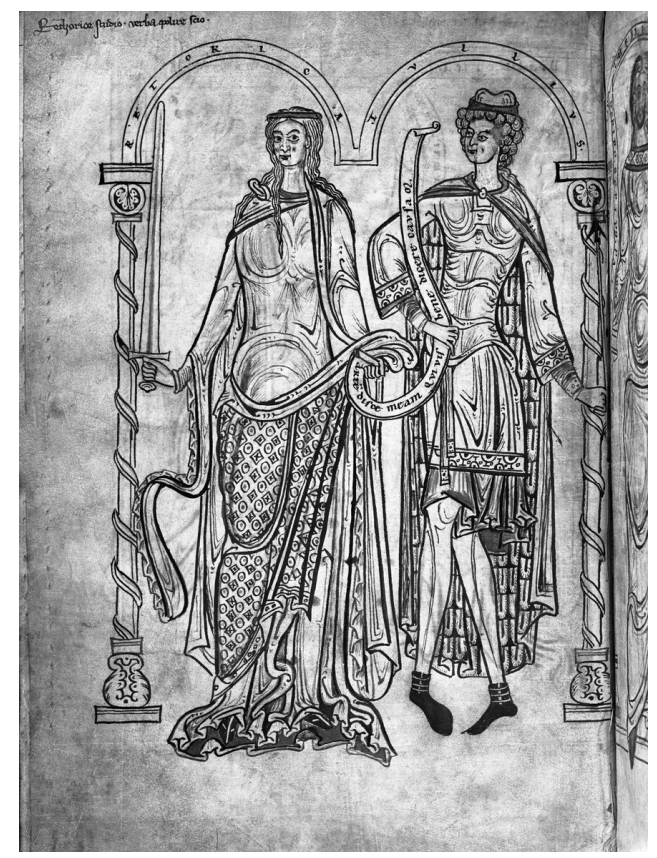

Fig. 1: Retórica y Cicerón. München, Bayerische Staatsbibliothek, Cod. lat. 2599, fol. 104v.

De nuevo aparece el autor del De inventione en el folio 109r, identificado por la inscripción Cicero Tullius, esta vez junto a su cabeza. ${ }^{16}$ Pero aquí es retratado a una edad madura con barba y pelo largo, al estilo de un profeta, y, a su lado, a la derecha, Marciano Capela (Martianus Capella). Ambos rétores están dentro de un arco doble como el anterior, en la parte izquierda del cual, sobre Cicerón, se lee la inscripción DICIMVS INNATA LEX y en sus manos porta una filacteria en el que leemos QVID SIT QVID POSITVRA. La parte final de la tercera sección es una galería de escritores ilustres similar a la representada siglos más tarde en el Studiolo de Federico da Montefeltro en el Palacio Ducal de Urbino.

16 Cf. Klemm 1998, 94. La miniatura del folio 109r está disponible en https://www.bildindex. de/document/obj00074132?part=22\&medium=mi02378c01 (visto 9.12.2019). 


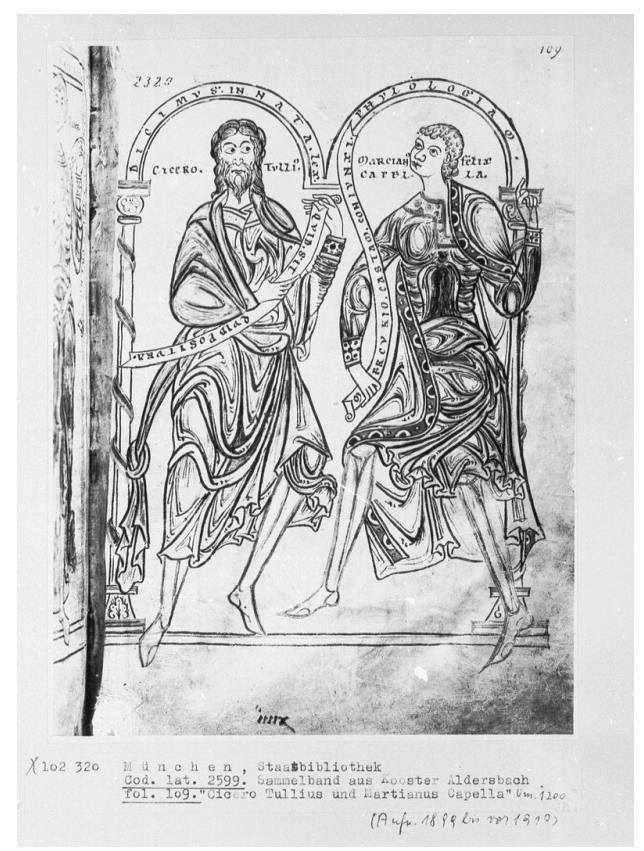

Fig. 2: Cicerón y Marciano Capela. München, Bayerische Staatsbibliothek, Cod. lat. 2599, fol. 109r.

2.2. Otro códice realizado en Padua alrededor de 1380, que contiene la Rhetorica ad Herennium y pertenece a manos privadas, ${ }^{17}$ está decorado con varias miniaturas que presumiblemente representan a Cicerón. En el folio 1r, dentro de la inicial E se ve a un profesor, vestido de rojo, con capa corta de armiño, similar a la que lleva en el retrato que le hizo Justo Gante para el Studiolo de Federico da Montefeltro en el Palacio Ducal de Urbino y a la que lleva Ovidio en el manuscrito Holkham Hall, MS 324, fol. 159v, que contiene el Ars amatoria. También lleva capucha roja quizá forrada de armiño. Está sentado en un escritorio con un libro abierto y mirando hacia abajo a otro personaje masculino retratado en un medaloón que forma parte de la decoración vegetal del borde. Ambos parecen dialogar porque están gesticulando con las manos. Según la descripción que ofrece Christie's, en el folio 10r el autor aparece en la inicial I con atuendo similar, de pie y sosteniendo un libro; en el folio 41r, dentro de la inicial A, con un tocado y un traje

17 Se puede ver en https://www.christies.com/lotfinder/Lot/cicero-pseudo-rhetorica-ad-heren nium-in-latin-2031471-details.aspx (visto 9.12.2019). Para la transmisión de esta obra y De inventione, cf. Reynolds 1983, 98-100, Taylor 1993 y Ward 2015, 307-308, 311-317 y 320. 


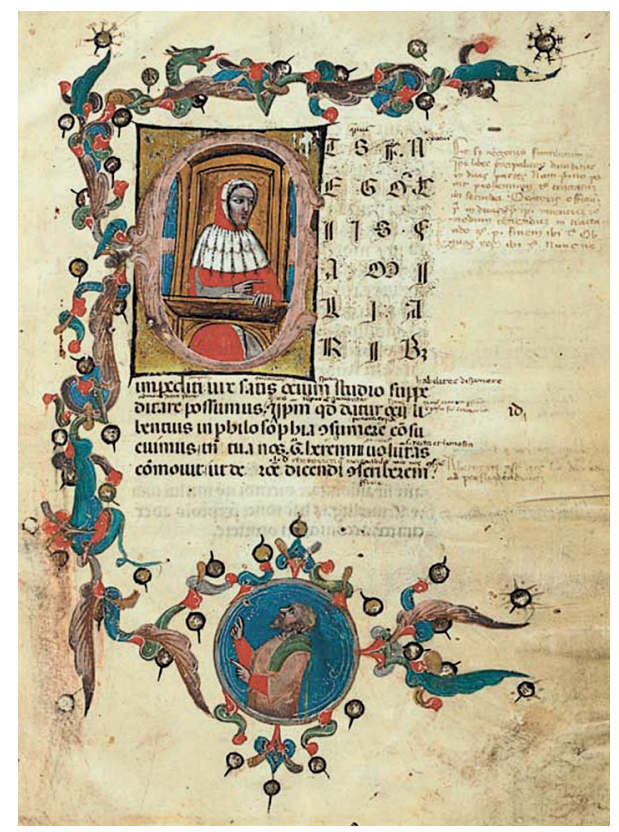

Fig. 3: Cicerón sentado in cathedra e impartiendo clases. Rhetorica ad Herennium (Padua c. 1380).

diferentes en actitud de hablar y, por fin, en el folio 61r, en el interior de la inicial Q, con un libro y moviendo las manos.

2.3. En el manuscrito italiano Venezia, Biblioteca Nazionale Marciana, Lat. XI, 143, fol. $1 \mathrm{r}$ de la Rhetorica ad Herennium, ${ }^{18}$ que data de $1335-1338$, hay una miniatura que representa a un Cicerón maduro con barba gris. El personaje es retratado con el birrete de los doctorandos que optaban a ingresar en el círculo de los doctores y que es símbolo tanto de investidura como de estatus. ${ }^{19}$ Está de pie sobre una tarima redonda pequeña pronunciando un discurso delante de un grupo numeroso de personajes masculinos con trajes académicos sentados a la derecha y a la izquierda. Algunos de ellos escuchan atentamente, mientras otros

18 Se puede ver la miniatura en https://www.gettyimages.es/detail/ilustraci\%C3\%B3n/the-spea ker-miniature-from-rhetorica-ad-herennium-gr\%C3\%A1fico-de-stock/142453490 (visto 9.12.2019) y en https://www.agefotostock.com/age/en/Stock-Images/Rights-Managed/DAE-11217837 (visto 9.12. 2019). Cf. Lazzi 2012, 55-56 y 74 (Tav. VII). Respecto a la datación, cf. Ward 2018.

19 Cf. Hülsen-Esch 1998, 242-244. 


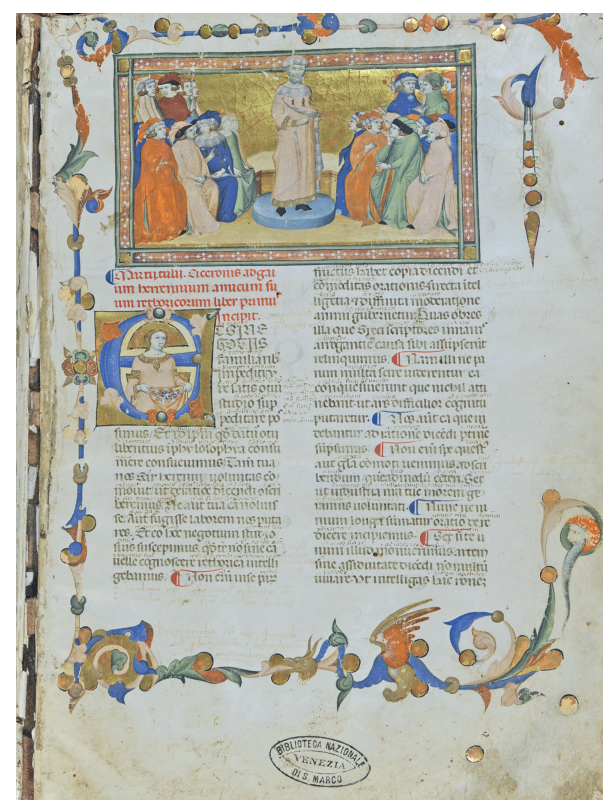

Fig. 4: Cicerón pronuncia un discurso. Venezia, Biblioteca Nazionale Marciana, Lat. XI, 143, fol. 1 r.

parecen comentar lo que está diciendo con otro colega. Es posible que la dama que aparece en la $E$ (inicial de etsi) sea una alegoría que representa a Retórica. ${ }^{20}$

2.4. Otro volumen que ofrece en su primer folio un retrato de busto muy detallado y realista de su supuesto autor es Città del Vaticano, Bibliotheca Apostolica Vaticana, Pal. lat. 1459, fol. $1 \mathrm{r}^{21}$ Confeccionado en Italia y datado entre los años 1376 y 1425 -aunque posiblemente la miniatura sea posteriorrecoge, entre otras obras, la Rhetorica ad Herennium y el De inventione. La inicial miniada $E(t s i)$ presenta a un Cicerón sin barba, de edad media y ataviado con túnica (o capa corta) azul con capucha azul y blanca (quizá porque el interior está forrado de armiño).

20 Cf. Ward 2018, VII.

21 Se puede ver en https://digi.vatlib.it/view/MSS_Pal.lat.1459; https://digi.vatlib.it/mss/detail/ 214099; https://digi.ub.uni-heidelberg.de/diglit/bav_pal_lat_1459 (visto 9.12.2019). 


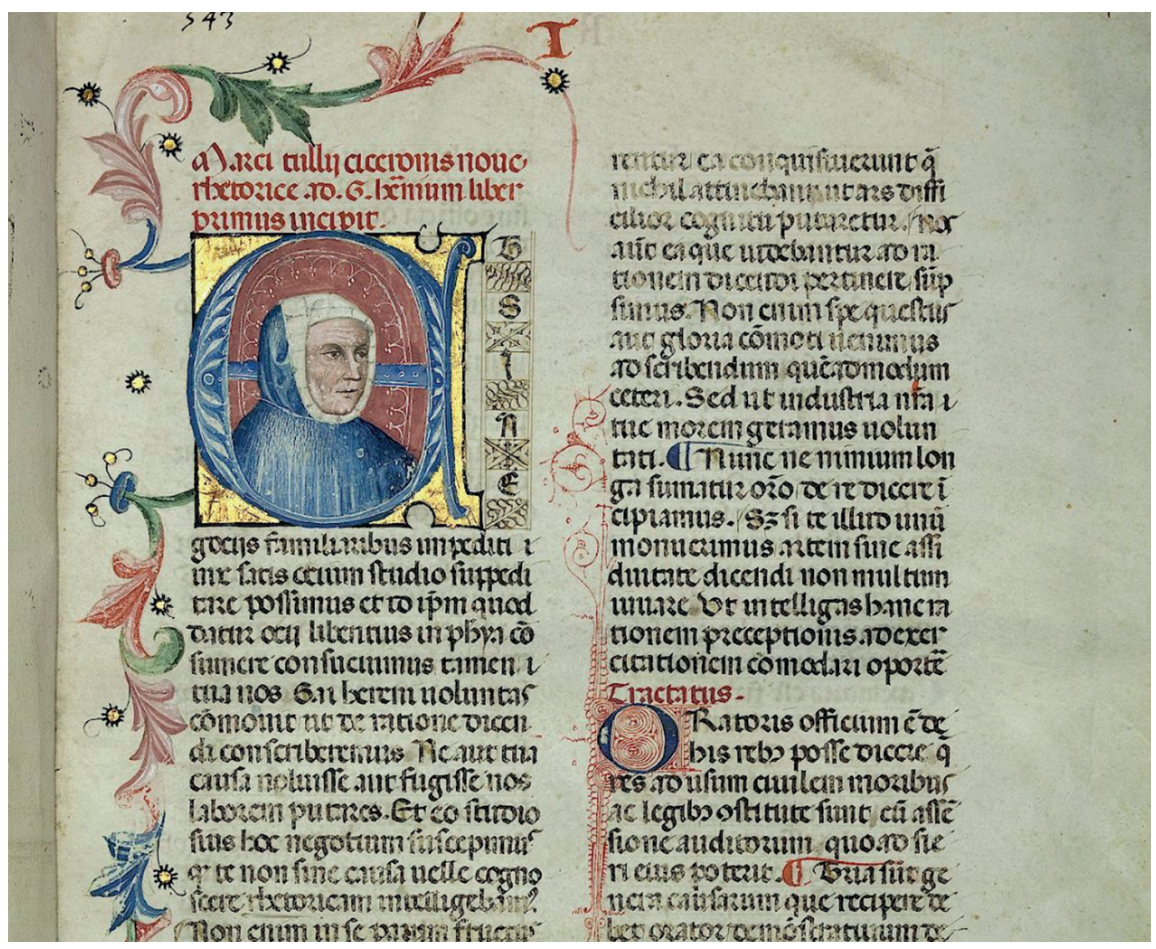

Fig. 5: Busto de Cicerón. Città del Vaticano, Bibliotheca Apostolica Vaticana, Pal. lat. 1459, fol. 1 r.

2.5. Por fin en el folio 240r. del manuscrito denominado Planetenkinder . Artes liberales, ${ }^{22}$ Salzburg, Universitätsbibliothek Salzburg, Cod. M III 36, realizado en Basilea entre 1400 y 1450, aparece en la mitad superior una dama joven cortando leña con un hacha que representa a la Retórica y en la parte inferior un personaje identificado con una inscripción en la que se lee Magister Tulius. Se trata de una especie de enciclopedia ilustrada que recoge, por un lado, los planetas y, por otro, un catálogo de las Artes Liberales y sus más conspicuos representantes (como ocurre en el BSB ms. lat. 2599 visto en el apartado 2.1.). Cicerón es retratado de cuerpo entero sentado in cathedra, ${ }^{23}$ con las manos

22 Se puede ver en: http://www.ubs.sbg.ac.at/sosa/handschriften/MIII36.htm (visto 9.12.2019) y. Se puede leer una descripción detallada en http://austriaca.at/0xc1aa5576\%200x002f4374.pdf (visto 9.12.2019)y http://www.handschriftencensus.de/10279 (visto 9.12.2019).

23 Esta es una forma muy común de representar, por ejemplo, a Ovidio (Martín Puente 2018, 33-39), Séneca (Martín Puente 2021b), Virgilio, Livio, etc. 


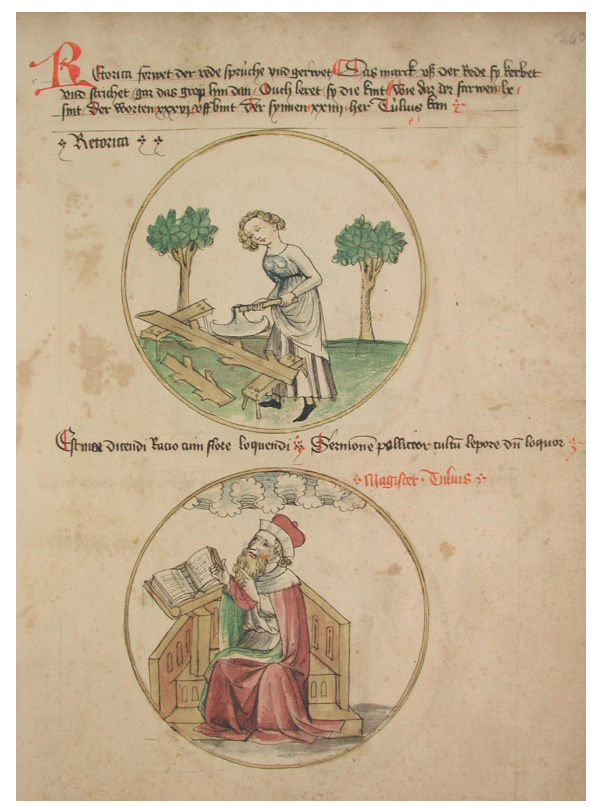

Fig. 6: Alegoría de la Retórica partiendo leña. Cicerón sentado in cathedra dictando de un libro que descansa sobre un atril. Salzburg, Universitätsbibliothek, M III 36, fol. 240 r.

levantadas en actitud de dictar de un libro que descansa sobre un atril, con capa roja por fuera y verde por dentro y un birrete parecido al que luce en el manuscrito recogido en 2.3. En esta ocasión lleva larga barba rubia. Sobre la joven aparece el nombre Retorica y sobre el autor aparece la leyenda Est mea dicendi ratio cum flore loquendi. Sermone polliceor cultum lepore dum loquor.

2.6. El manuscrito Paris, Bibliothéque Nationale de France, Latin $7789,{ }^{24}$ confeccionado en París y datado entre 1405 y 1410, contiene el Pro Marcello en latín, el De senectute en latín y la traducción al francés que Laurent de Premierfait realizó de esta obra en 1405 y tituló Livre de vieillesse. ${ }^{25}$ En los folios 8r, 37r y 39r encontramos tres retratos de Cicerón realizados por el iluminador conocido como El Maestro de Cleres femmes o por su círculo. El Pro Marcello, que ya citan los gramáticos latinos, gozaba de bastante fama en la Edad Media y el Renacimiento, como también ocurría con las obras filosóficas de Cicerón. ${ }^{26}$

24 Se puede visualizar en: https://gallica.bnf.fr/ark:/12148/btv1b84516084 (visto 9.12.2019). Sobre este manuscrito, cf. Pellegrin 1958 y Hedeman 2004a y 2008.

25 Cf. Marzano 2008 y 2009.

26 Sobre la gran tradición manuscrita del De senectute, cf. Reynolds 1983, 116-120; Ward 2015, 319. Respecto al Pro Marcello, cf. Reynolds 1983, 55, 57-62; 65-67; Morrás 1991, 221; Lorenzi 2013. Hay otros manuscritos, sobre todo franceses, que incluyen juntos los discursos cesarianos 
Premierfait experimentó con el empleo de ilustraciones para acercar aún más la traducción de este texto de la Antigüedad a su tiempo. ${ }^{27}$ Él mismo ${ }^{28}$ aparece en el folio $34 \mathrm{r}$ entregando el libro a Luis de Borbón, a quien se lo dedica, de la misma manera que en manuscritos que contienen la obra de Tito Livio aparecen retratos de su traductor francés Pierre Bersuire. ${ }^{29}$

En el folio $8 \mathrm{r}$-dentro del prólogo latino del tratado De senectute-, aparece por primera vez Cicerón, con el traje académico y birrete negro en su cabeza. Está sentado in cathedra en un paisaje exterior con cielo azul y tres árboles y encomienda una copia encuadernada en rojo a un joven, que vuelve a aparecer entregándosela a otro varón sabio con túnica que no llega hasta el suelo y barba bifurcada larga y oscura como su pelo. Hay discrepancias en cuanto a quiénes son los tres personajes. ${ }^{30}$ Esta ilustración tiene su equivalente en el folio $9 \mathrm{r}$ del manuscrito Milano, Biblioteca Trivulziana 693 (cf. 2.7).

y el De senectute, pero sin retratos. En general los manuscritos con las obras filosóficas son muy numerosos en el siglo XV.

27 Cf. Hedeman 2004a, 59-60 y 2008, 24-30.

28 También hay un retrato de la escena en que Premierfait presenta el libro a Jean, Duque de Berry en el manuscrito Walters Ms. W.312, fol. 1r (Brujas c. 1470), que contiene la traducción que hizo del De amicitia (De la vraye amistie).

29 Por ejemplo, en BnF Arsenal 3693, fol. 9 y en BnF français 33, fol. 2.

30 Cf. Pellegrin 1958, 278; Hedeman 2004a, 59-60; 2008, 24-30. 


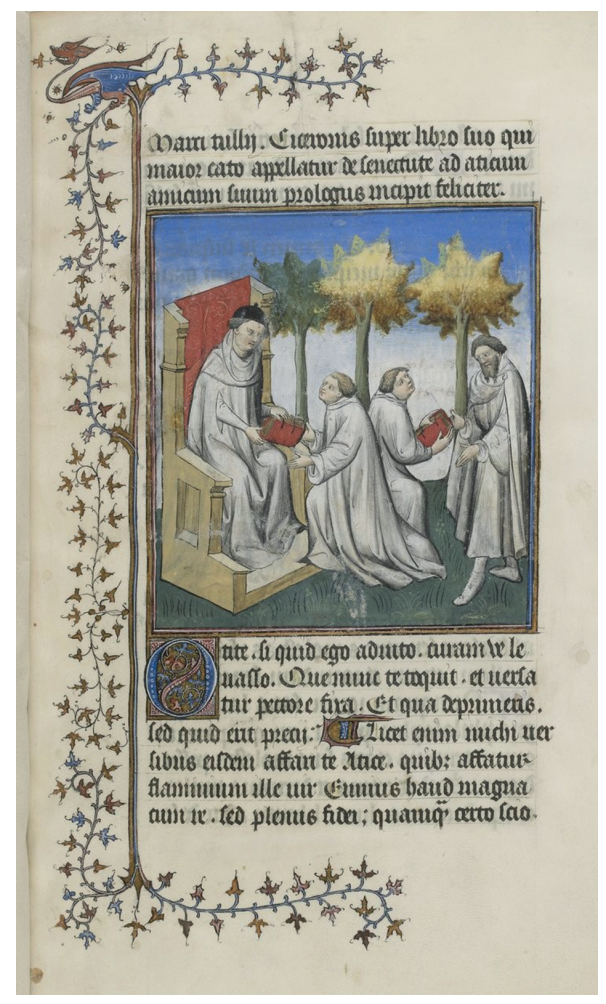

Fig. 7: Cicerón sentado in cathedra encomienda su libro a un joven para que se le entregue a otro varón docto. Paris, Bibliothéque Nationale de France, Latin 7789, fol. 8 r.

En la segunda ilustración, que aparece en el folio 37r, el artista presenta a Cicerón y a Catón, ataviados como académicos de la época, de pie delante de un Ático de edad avanzada (como indican su barba y su pelo blancos), que está sentado in cathedra con una túnica larga de académico que tapa sus pies y un tocado en la cabeza. Lo flanquean dos jóvenes que llevan vestimenta típica de la época, pero no de los académicos. 


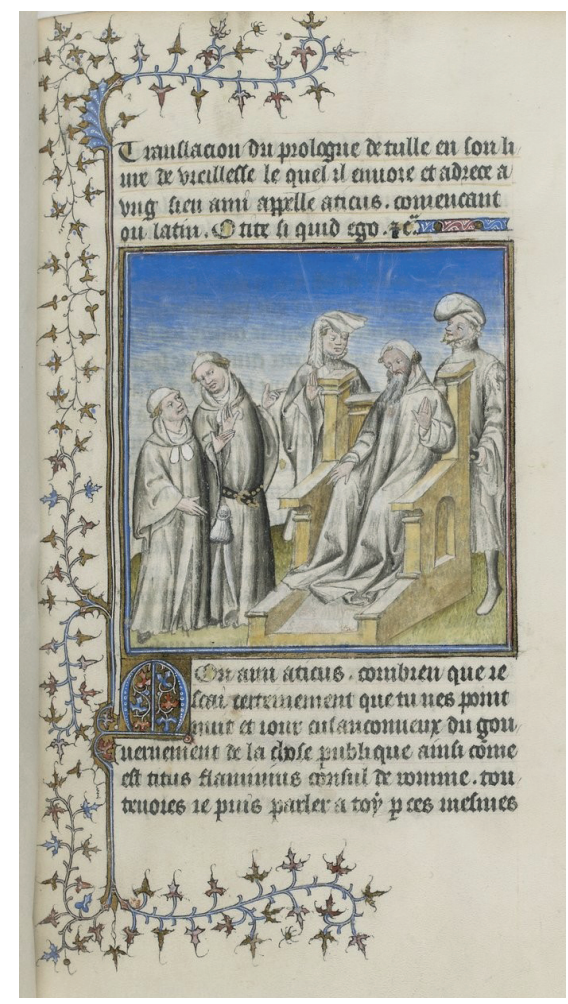

Fig. 8: Cicerón y Catón de pie delante de Ático sentado in cathedra y flanqueado por does jóvenes. Paris, Bibliothéque Nationale de France, Latin 7789, fol. 37r.

En la miniatura del folio 39r Cicerón está hablando a Escipión y Lelio. ${ }^{31}$

31 Esa es la opinión de Pellegrin 1958, 278 - 279. Según Hedeman 2008, 28, no es Cicerón, sino Catón. 


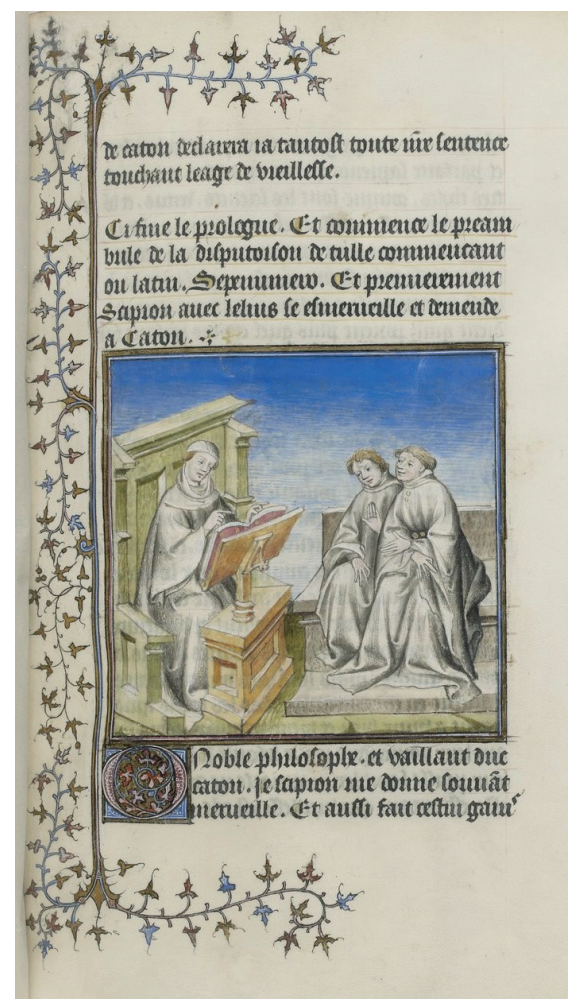

Fig. 9: Cicerón habla a Escipión y Lelio. Paris, Bibliothéque Nationale de France, Latin 7789, fol. 39r.

2.7. Existe una copia casi gemela del anterior códice, el manuscrito Milano, Biblioteca Trivulziana, Triv. 693 (datable entre 1426 y 1450). Contiene las mismas obras, Pro Marcello, De senectute y la traducción que hizo al francés Premierfait (Livre de vieillese), pero menos ilustraciones. El folio 9r es casi idéntico al 8r del BnF, Latin 7789. ${ }^{32}$

32 Tenemos la imagen en: https://manus.iccu.sbn.it//opac_viewImmaginiManoscritto.php?ID= 105321 (visto 9.12.2019). El folio 33r corresponde al 34r del BnF man. Latin 7789. Cf. Pellegrin 1958. 


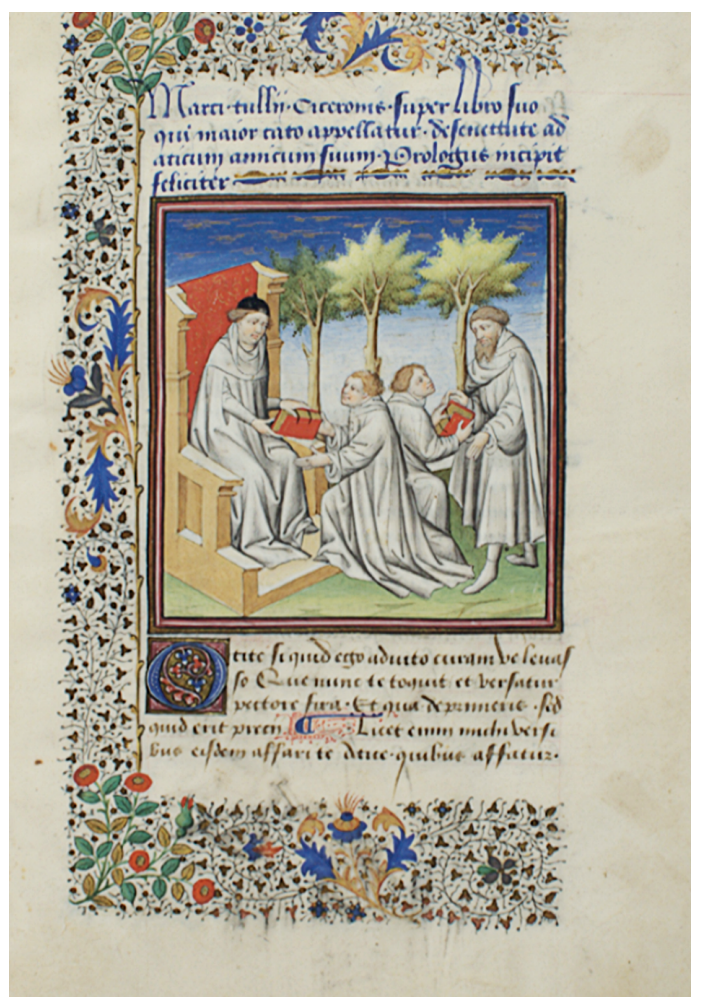

Fig. 10: Cicerón sentado in cathedra encomienda su libro a un joven para que se le entregue a otro varón docto. Milano, Biblioteca Trivulziana, Triv., 693, fol. 9r.

2.8. La traducción al castellano que hizo Alfonso de Cartagena del tratado De officiis, ${ }^{33}$ del tratado De senectute encargadas ambas por el secretario del rey Juan II de Trastámara, Juan Alfonso de Zamora para uso del entonces príncipe Duarte de Portugal- y del discurso Pro Marcello se recogen en un manuscrito realizado en España en la primera mitad del siglo XV, el London, British Library, Harley MS $4796 .^{34}$ Dentro de la inicial O del folio 66r hay una miniatura que pone en escena a Cicerón dialogando supuestamente con su hijo. Los dos aparecen sentados. Cicerón lleva un atuendo parecido al que viste en el BnF, Latin 7789,

33 La obra De officiis tuvo menos éxito que las anteriores (Reynolds 1986, 130 -131; Ward 2015, 315, 319, 322), pero los humanistas encontraron representado en ella el ideal humanidad.

34 Se puede ver en: https://www.bl.uk/catalogues/illuminatedmanuscripts/record.asp?MSID= 8166\&CollID=8\&NStart=4796 (visto 9.12.2019). Cf. Morrás 1991, 221; 1996, 106-108; Baldissera 2003, 67-68. 


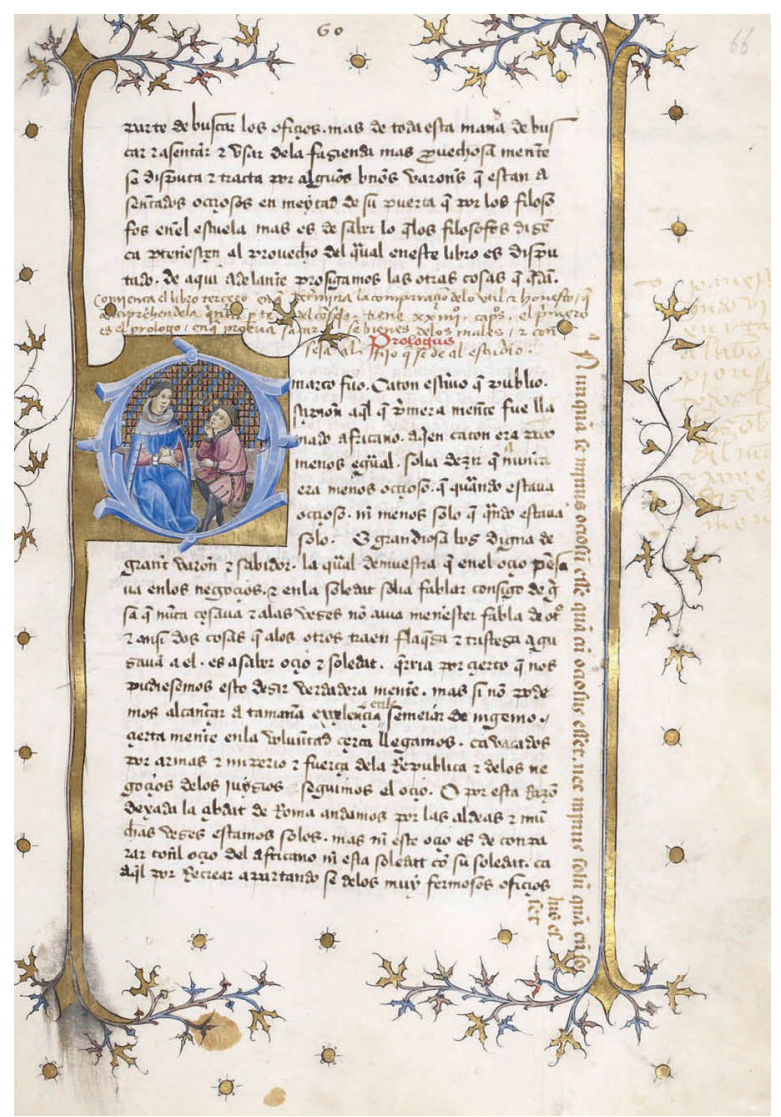

Fig. 11: Cicerón dialogando supuestamente con su hijo. London, British Library, Harley MS 4796, fol. 66r.

fol. $8 \mathrm{r}$ (2.6.) de un azul intenso, con capa corta de azul claro y birrete negro que lo identifica como doctor o magister.

2.9. Otra maravillosa miniatura ocupa media columna de las dos que tiene el folio $1 \mathrm{r}$ de un manuscrito magníficamente decorado y copiado en Francia entre finales del siglo XIV y pricipios del siglo XV, el Città del Vaticano, Biblioteca Apostolica Vaticana, Pal. lat. 1523. Incluye obras de Cicerón, un texto de Jerónimo, el De amicitia, un Accesus a este tratado y otras obras atribuidas erró- 
neamente al arpinate. ${ }^{35}$ La obra que aborda el tema de la amistad era muy conocida en la Edad Media, por ejemplo, por Eloísa, Abelardo, ${ }^{36}$ y Dante, a quien impulsó a estudiar filosofía. En la ilustración aparecen sentados en el poyo de una ventana de castillo gótico dos personajes con toca y con barba que presumiblemente son Cicerón y Ático de edad madura. Cicerón, a la izquierda, con túnica roja abierta por el lateral izquierdo y forrada de piel, o bien una capa, que permite entrever un sayo rojo debajo, con la mano derecha levantada, en actitud de hablar, y Ático, a la derecha, de azul, estaría escuchando muy atento, con las manos entrelazadas sobre el regazo. Ambos llevan en la cabeza una prenda muy parecida a la de Boccaccio en el retrato que le hiciera Andrea del Castagno (1423-1457) o en el fresco de las Artes Liberales (finales del siglo XV) en la Capilla de Invierno de la Catedral de Nôtre Dame de Le Puy-en-Velay.

Dentro de este mismo códice, en el folio 33r, al comienzo del De senectute, hay otro personaje masculino anciano y sabio, a juzgar por su barba larga y blanca bifurcada, como en manuscritos ya vistos anteriormente, y por el bastón de la mano derecha. No es fácil dilucidar si está de pie o sentado apoyándose en el brazo de una silla o sillón, pero lleva la misma indumentaria que Ático en la miniatura anterior, excepto por lo que respecta al tocado de la cabeza. Dado que el título de la obra es Cato maior, probablemente se trata de Catón.

35 Está disponible en: https://digi.ub.uni-heidelberg.de/diglit/bav_pal_lat_1523/0011/image (visto 9.12.2019).

36 Cf. Reynolds 1983, 121-124; Ward 2015, 309, 319, 322, 325-326. 


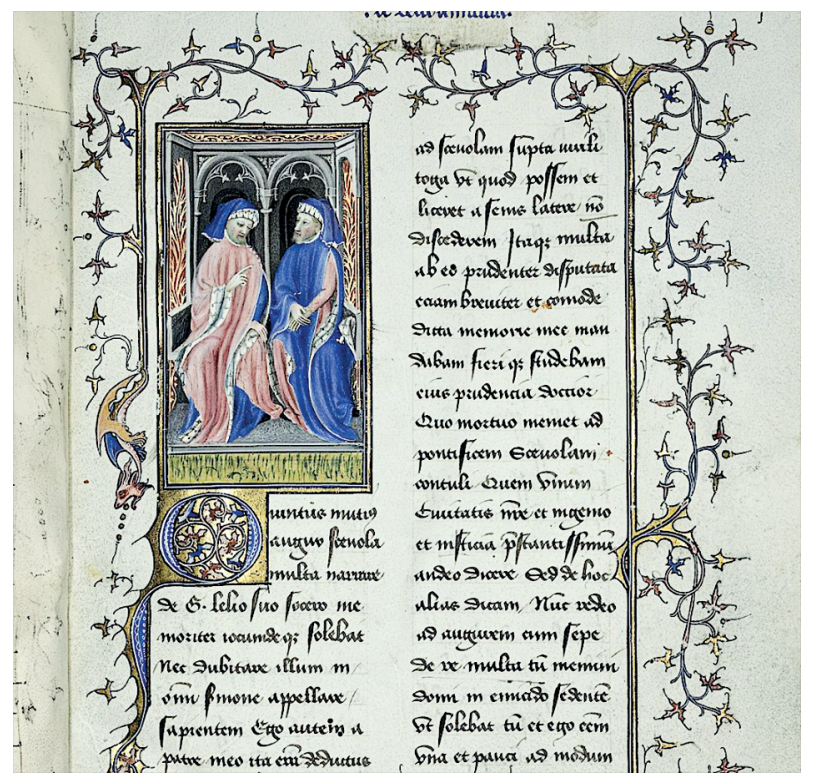

Fig. 12: Cicerón y Ático dialogan sentados en el poyo de una ventana. Città del Vaticano, Biblioteca Apostolica Vaticana, Pal. lat. 1523, fol. 1r.

2.10. El manuscrito London, British Library, Harley 4329 (Tours? 1460), ${ }^{37}$ ricamente decorado, recoge la traducción al francés por Laurent de Premierfait del tratado De amicitia de Cicéron (Le livre de l'amitié). En la primera página de esta traducción (fol. 130) hay una gran ilustración (del Maestro del Boccaccio de Múnich, quizá Louis Fouquet o François Fouquet) con Cicerón sentado en cátedra en actitud de hablar a un varón que le escucha a la izquierda de la escena, mientras otro a la derecha presencia la conversación. Viste túnica blanca y capa con capucha azul. El marco arquitectónico es un espacio abovedado con numerosas nervaduras marcadas por finos baquetones, que se unen en el centro y descansan sobre una columnilla que sirve de eje compositivo.

37 Se puede ver en:http://www.bl.uk/catalogues/illuminatedmanuscripts/record.asp?MSID= 6578 (visto 9.12.2019). 


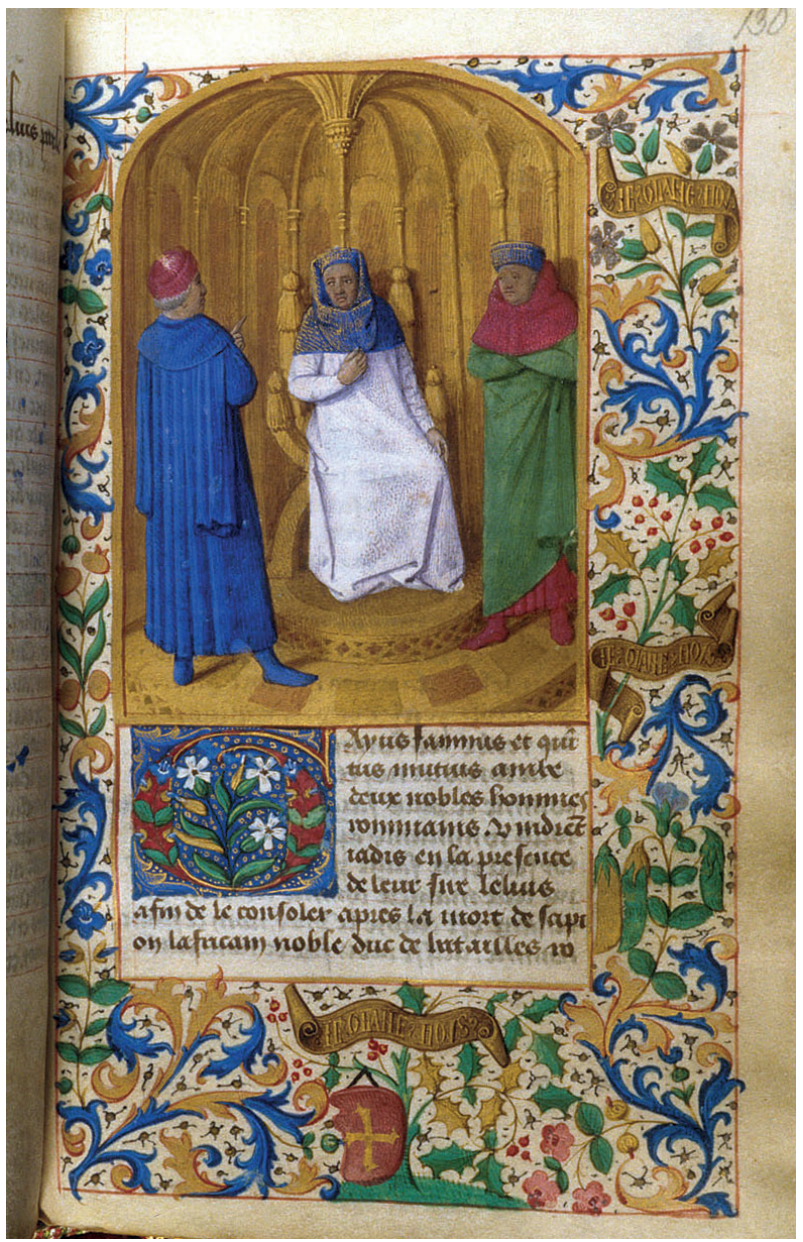

Fig. 13: Cicerón sentado in cathedra habla a un varón en presencia de orto. London, British Library, Harley 4329, fol. 130.

2.11. Tenemos otros dos retratos de Cicerón en el manuscrito New York, Pierpont Morgan Library, MS. M.1002, fol. 2v y fol. 71r, ${ }^{38}$ que fue realizado en 1410 en Signa (Italia) y contiene el tratado De finibus bonorum et malorum. El primero ocupa todo el folio $2 \mathrm{v}$ y muestra al personaje con barba blanca de pie soste-

38 Disponible en: https://www.themorgan.org/manuscript/160110 (visto 9.12.2019). Sobre la transmisión de este tratado, que se recoge en muchos manuscritos de los siglos XIV y XV, sobre todo italianos, quizá derivados del círculo de Petrarca, cf. Reynolds 1983, 112-115 y Ward 2015, 322-323. 


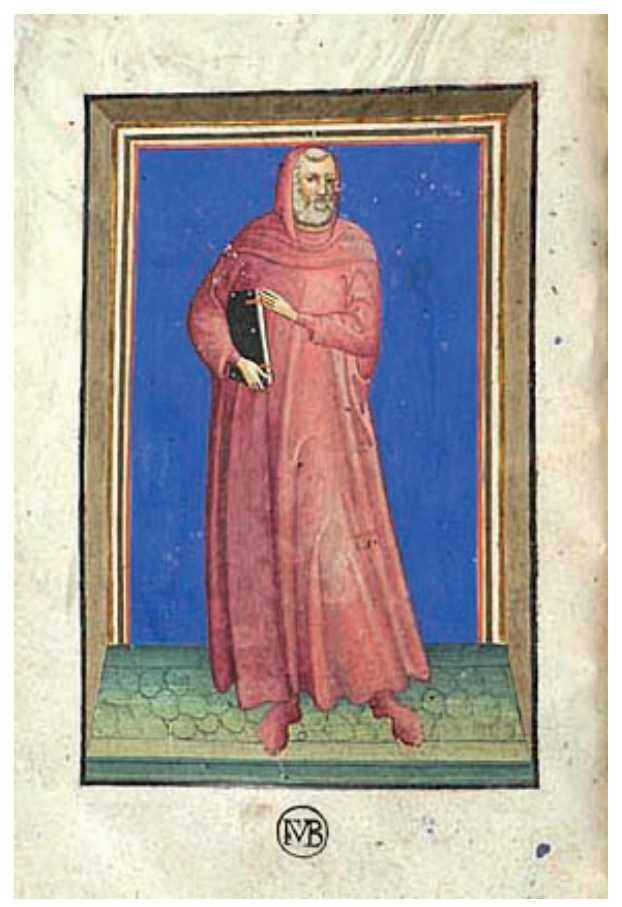

Fig. 14: Cicerón de pie sostiene un libro con dos broches debajo del brazo derecho. New York, Pierpont Morgan Library, MS. M.1002 fol. 2v.

niendo el libro con dos broches debajo del brazo derecho. Lleva una túnica roja con capucha, muy similar a la que portan Petrarca y Dante en los retratos que hiciera Andrea del Castaño para la Serie de hombres y mujeres famosos de Villa Carducci en Legnaia entre 1448 y 1451. Como en estos casos, Cicerón está delante del marco de una puerta vestido de rojo coral y su figura se destaca sobre un fondo de azul intenso.

En el folio 71r encontramos dentro de la inicial $C(u m)$ un retrato de busto del autor con capucha roja y túnica verde..$^{39}$ Sus manos están entrelazadas y con el antebrazo izquierdo sujeta un libro rojo. Esta pequeña representación es también muy similar a los retratos de Petrarca de esta época tanto en miniaturas como en pintura de gran formato, así como, por ejemplo, a los de Séneca que encontramos en los manuscritos BL King's 30, fol. 2. y BL Harley 2483, fol. 2.

39 Se puede ver en: http://ica.themorgan.org/manuscript/page/2/160110 (visto 9.12.2019). 


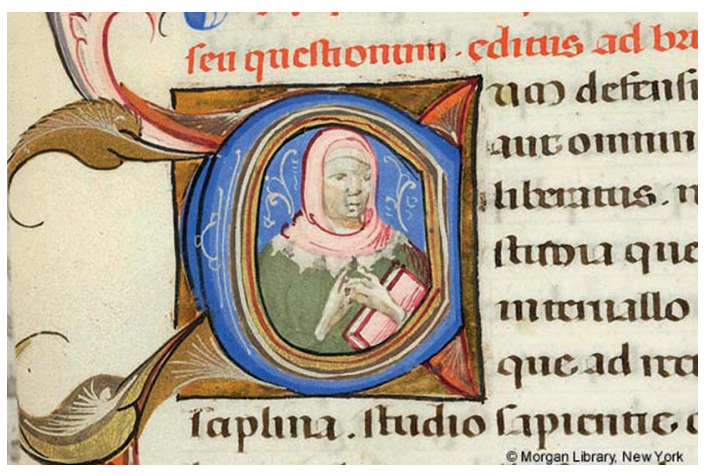

Fig. 15: Busto de Cicéron dentro una inicial. New York, Pierpont Morgan Library, MS. M.1002 fol. 71 .

2.12. El manuscrito del siglo XV Madrid, Biblioteca Nacional de España, RES/ 236, ${ }^{40}$ nos transmite una traducción al italiano de los tratados De officiis, De amicitia, Paradoxa Stoicorum y De senectute. Todos los tratados comienzan con una inicial miniada, pero solo el primero tiene además un retrato del autor latino en el folio 1r. dentro de la inicial dorada A sobre fondo azul decorado. Dos putti sujetan la inicial y una filacteria en la que se lee MARCO TVLIO CICERONE, de modo que no cabe ninguna duda de quién es el personaje retratado. El autor es representado con cabellera y barba largas y completamente blancas, es decir, como un hombre sabio. Lleva un traje rojo forrado de verde y gorro rojo y blanco. Sujeta en su mano izquierda un enorme libro azul cerrado. Este retrato se parece bastante al de Séneca de cuerpo entero escribiendo en el manuscrito del siglo XV Madrid, Biblioteca Nacional de España, RES/7, fol. 7, donde se recogen las traducciones también al italiano de las Epistulae morales ad Lucilium y del De providentia y la correspondencia entre Agustín de Hipona y Bonifacio.

40 Se puede ver en: http://bdh.bne.es/bnesearch/detalle/bdh0000188485 (visto 9.12.2019). 


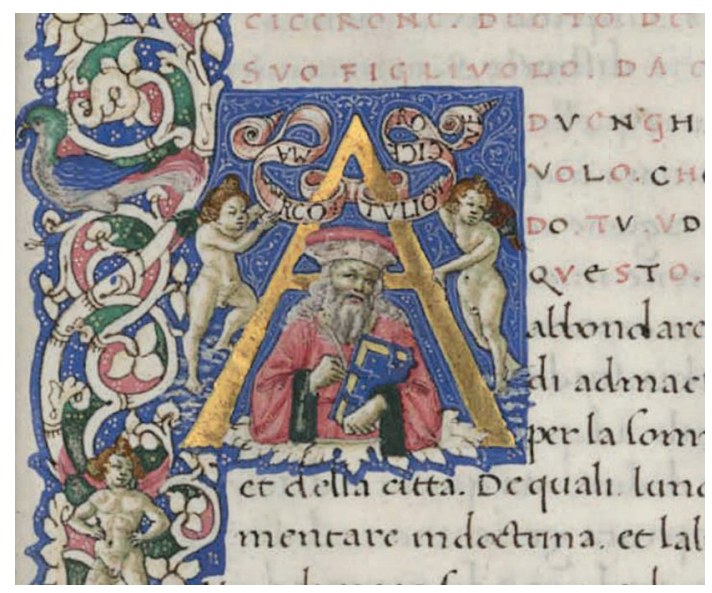

Fig. 16: Busto de Cicerón dentro de inicial dorada. Madrid, Biblioteca Nacional de España, RES/236, fol. 1 r.

2.13. Tras una primera traducción al francés en 1400, en 1409 Laurent de Premierfait concluyó una segunda traducción de la obra de Giovanni Boccaccio ${ }^{41}$ que lleva por título De casibus virorum illustrium (entre 1355 y 1374), bajo el título Les Cas des nobles hommes et femmes, que el traductor quiso se decorara con miniaturas. ${ }^{42}$ Dentro de la $\mathrm{T}$ inicial que abre el capítulo 12 del libro 6, del manuscrito Rouen, Bibliothèque Municipale, 1440, f. 213v (Francia, segundo tercio del siglo XV), ${ }^{43}$ junto a la rúbrica «Le XII chapitre contient le cas du noble philozophe et prince de eloquence Tulles consul rommain», el interior de una habitación muestra a un soldado que está a punto de decapitar, espada en mano, al autor de las Catilinarias, que está arrodillado con una mano en el pecho y la otra extendida y con la cabeza inclinada hacia delante. Ya ha debido de asestarle un golpe porque, aunque los personajes no están coloreados, del cuello de Cicerón, chorrea sangre roja. El personaje tiene cara juvenil, va vestido

41 Sobre el conocimiento que este poeta tenía de Cicerón, cf. Reynolds 1983, XL, 71, 86 - 88, 94 y 430. Por su parte, Boccaccio es retratado por Jean Fouquet escribiendo en su estudio mientras un mensajero lleva su obra a Meinardo dei Cavalcanti en BSB Cod. Gall. 6, fol. 10 (Bretaña?, siglo XV) y en BL Royal 14 E V, fol. 391 (Brujas c. de 1479) junto a Petrarca en una biblioteca leyendo libros.

42 Respecto a los manuscritos con las traducciones francesas de Boccaccio, cf. Bozzolo 1972 y Hedeman 2004a; 2004b; 2008, 55-128 y Swift 2016.

43 La miniatura se puede ver en: http://initiale.irht.cnrs.fr/decors/decors.php?id=58995\&inde xCourant=110\&bloc_recherche_decor=none\&bloc_resultats_decor=none\&resetForm=1\&page= 1\&ouvrageId=3914\# (visto 9.12.2019). 


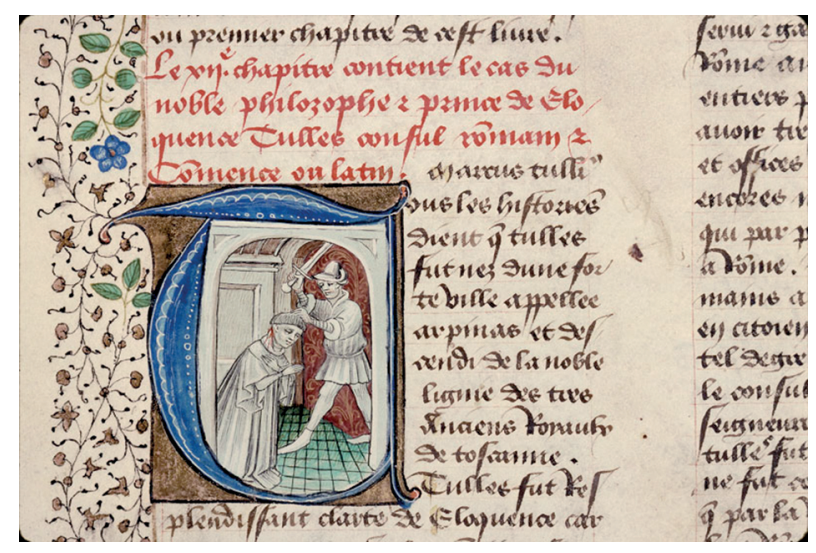

Fig. 17: Cicerón arrodillado a punto de ser decapitado por un soldado, dentro de una T inicial. Rouen, Bibliothèque Municipale, 1440, fol. 213v.

con el traje académico y lleva birrete o bien un corte de pelo a modo de casquete. El tratamiento que hace Boccaccio de Cicerón tenía también la intención de ilustrar la inestabilidad de los logros humanos, según se desprende de la frase huius ergo clarissimi viri gloria licet grandis fuerit non tamen solida. ${ }^{44}$ El tema de la muerte de Cicerón se hará más tarde muy recurrente en el arte. Por ejemplo, en La muerte de Cicerón (c. 1635) de François Perrier (Bad Homburg, Alemania, Staatliche Schlösser), donde Herenio, tras interceptar con sus hombres la litera de Cicerón, se dispone a decapitarlo; en La ira de Fulvia (c. 1692) de Gregorio Lazzarini (Museumslandschaft Hessen Kassel, Alemania); o en un grabado realizado por Christian Bernhard Rode en 1775 que se guarda en el British $\mathrm{Mu}$ seum y representa a Cicerón sentado en una litera al que se aproxima Herenio para matarlo con su espada. ${ }^{45}$

2.14. Existe otro manuscrito realizado en Brujas entre 1479 y1480 con esta misma traducción del De casibus virorum illustrium que hizo Premierfait, el London, British Library, Royal 14 E V, que muestra en el folio 334 a Cicerón decapitado desplomado en el suelo boca abajo y al centurión, con armadura y casco y sonriendo casco, que sonríe, sosteniendo su cabeza clavada en una lanza y su mano derecha amputada clavada en una espada. Esta vez los dos personajes están en un camino a campo abierto en un paisaje idílico con prado, río, árboles, montañas y cielo azul.

44 Cf. Jones/Kilpatrick 2007, 376.

45 Martín Puente 2021a. 


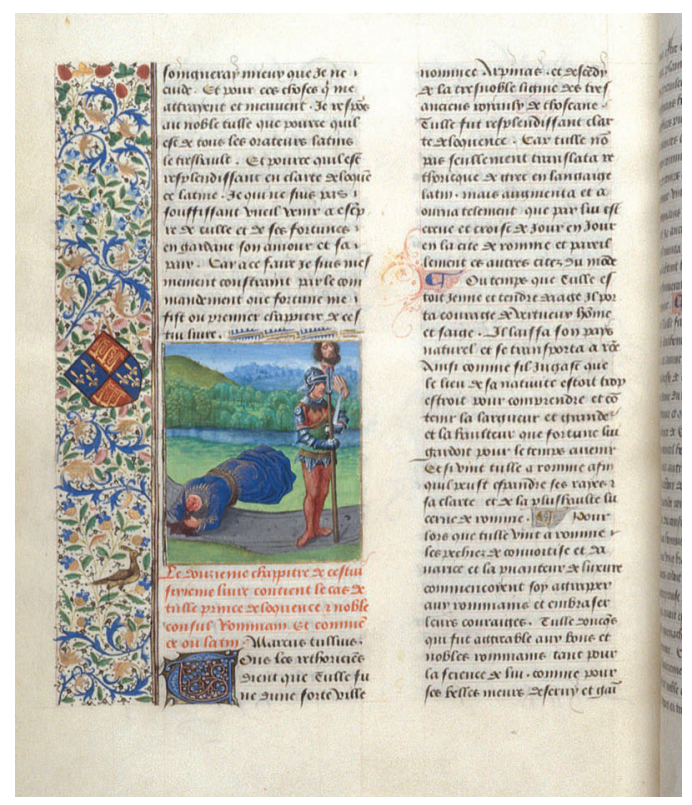

Fig. 18: Cicerón decapitado yace en el suelo, mientras un soldado sostiene su cabeza en una Lanza y su mano derecha en una espada. London, British Library, Royal 14 E V fol. 334.

\section{Conclusiones}

El repertorio que acabamos de mostrar nos permite concluir que existen numerosos retratos de Cicerón en manuscritos europeos desde principios del siglo XIII hasta finales del siglo XV. Muchos de ellos aparecen en códices que recogen la Rhetorica ad Herennium, los tratados filosóficos De amicitia, De senectute, De officiis y De finibus o el discurso Pro Marcello. La efigie puede estar incluida dentro de una inicial, ocupar buena parte del folio o llenar incluso el folio entero. También encontramos a Cicerón acompañando a Retórica dentro de una colección de representaciones de las Artes liberales acompañadas por sus respectivos máximos cultivadores, dado que durante la Edad Media y parte del Humanismo fue el máximo exponente de esta disciplina. Y, después, en la galería de los autores latinos canónicos (Virgilio, Ovidio, Lucano, etc.), vemos al arpinate en el mismo folio que Marciano Capela. Se trata de una galería de hombres ilustres similar a las que adornan bibliotecas, palacios y catedrales. Finalmente, en tanto que ciudadano ejemplar, ilustra el apartado sobre la decapitación de Cicerón de la traducción al francés que Premierfait hizo del De casibus virorum illustrium de Boccaccio. 
En cuanto al retrato mismo, a veces es un busto que no forma parte de una escena -como los que representan muchas esculturas desde la Antigüedad-, otras veces Cicerón aparece escribiendo o leyendo en cátedra (como muchos otros escritores en la Edad Media), dialogando con Catón, Ático, su hijo u otros personajes aún no identificados (no hay que olvidar que sus obras filosóficas son diálogos) o impartiendo una lección magistral ante un público en el ámbito académico. Podemos verlo con las facciones de un varón joven, de edad madura o de edad avanzada. Puede ir sin barba o con barba negra, rubia o blanca (esta última, además de la edad, simboliza la sabiduría). Aparte de algún caso en el que tiene los rasgos de un profeta con cabellera y barba largas, lo normal es que vista el traje típico de los doctorandos, doctores y magistri (en rojo, azul o blanco), una capa corta, a veces, y el birrete negro o algún otro tipo de tocado similar a los que llevan los humanistas italianos. De hecho, en alguna de las miniaturas se asemeja mucho a los retratos contemporáneos de Petrarca, Boccaccio o Dante, personajes cuya fisionomía sí conocía el público. En algunas ocasiones la imagen aparece identificada por una inscripción con su nombre o está muy cerca del encabezamiento donde aparece el nombre del autor y de la obra. 
